\title{
Betrachtung mikrobieller Veränderungen in österreichi- schen Uferfiltraten mittels High-Throughput-Sequencing und Durchflusszytometrie
}

\author{
C. J. Fiedler · C. Schönher · P. Proksch · D. J. Kerschbaumer · E. Mayr · M. Zunabovic-Pichler $\cdot$ R. Perfler
}

Online publiziert: 7 . Oktober 2020

(C) Der/die Autor(en) 2020

Zusammenfassung Trinkwassergewinnung mittels Uferfiltration gewinnt weltweit und auch in Österreich zunehmend an Bedeutung. Entlang der Donau existieren verschiedene Uferfiltratstandorte, deren Brunnen zu verschiedenen saisonalen Zeitpunkten 2016 und 2017 mittels High-Throughput-Sequencing (Ermittlung der mikrobiellen Zusammensetzung bzw. des Mikrobioms) und mittels Durchflusszytometrie (Gesamtzellzahl) untersucht wurden. Dabei konnten räumliche Unterschiede zwischen den Brunnenfeldern, saisonale Änderungen sowie insbesondere Einflüsse durch Hochwasserereignisse festgestellt werden. Die Erweiterung der Datenbasis durch die Hinzunahme von Sequenzierungsdaten einer Donau-Studie zeigt interessante Möglichkeiten, vorhandenes Wissen mit bioinformatischen Mitteln einzubinden und neue Erkenntnisse zu generieren.

Schlüsselwörter Grundwasser Uferfiltrat · Mikrobiom · HighThroughput-Sequencing . Durchflusszytometrie

DI C. J. Fiedler $(\bowtie)$

DI C. Schönher · DI P. Proksch .

DI D. J. Kerschbaumer, B.Sc. .

DI Dr. M. Zunabovic-Pichler .

PD DI Dr. R. Perfler

Institut für Siedlungswasserbau,

Industriewasserwirtschaft

und Gewässerschutz (SIG),

Universität für Bodenkultur Wien,

Muthgasse 18, 1190 Wien, Österreich

christina.fiedler@boku.ac.at

DI E. Mayr

MA 31 - Wiener Wasser,

Grabnergasse 4-6, 1061 Wien,

Österreich
Analysis of microbial changes in Austrian river bank filtrates using high-throughput sequencing and flow cytometry

Abstract The production of drinking water by means of river bank filtration is becoming increasingly important worldwide and also in Austria. Along the Danube, there are various bank filtration sites, whose wells were investigated at different seasonal times in 2016 and 2017 by means of high-throughput sequencing (determination of microbial composition) and flow cytometry (total cell count). Spatial differences between the well fields, seasonal changes and especially influences by flood events could be detected. The extension of the data set by adding sequencing data of a previous Danube study shows interesting possibilities to integrate existing knowledge with bioinformatic tools and to generate new findings.

Keywords Groundwater - River bank filtrate $\cdot$ Microbiome $\cdot$ High-throughput sequencing $\cdot$ Flow cytometry

\section{Einleitung}

Grundwasser stellt die wichtigste natürliche Ressource von Trinkwasser weltweit dar. Aufgrund natürlicher Filtrationsprozesse durch die Erdoberfläche wird das Wasser gereinigt, gleichzeitig werden Nährstoffe durch verschiedenste Mikroorganismen um- und abgebaut, sodass ein oligotrophes Wasser entsteht (Bannick et al. 2008). Die sich im Wasser befindenden Mikroorganismen stellen gemeinsam ein stabiles Ökosystem dar, welches auf das geringe Nährstoffvorkommen sowie die abiotischen Umstände angepasst ist. Sie bilden eine autochthone Gemeinschaft (Karczewski et al. 2017). Dabei ist die Anzahl der Mikroorganismen im Grundwasser im Vergleich zu denen im
Oberflächenwasser ca. um den Faktor zehn bis 100 geringer (Pedersen 2000).

Die große Mehrheit (über 99,9\%) der Mikroorganismen im Grundwasser ist zwar lebensfähig, aber nicht kultivierbar. Sie werden mit herkömmlichen kultivierungsbasierten Verfahren, die auch für die Beurteilung der mikrobiellen Trinkwasserqualität herangezogen werden nicht erfasst (Raes und Bork 2008). Inzwischen ist es anhand molekularbiologischer Methoden möglich, die Gesamtheit aller Mikroorganismen eines Ökosystems (das Mikrobiom) zu erfassen. Im Rahmen des High-Throughput-Sequencing werden Mikroorganismen aufgeschlossen und ein für taxonomische Untersuchungen geeigneter Abschnitt der DNA (16S-rRNA) extrahiert, vervielfältigt und die Nukleotid-Abfolge bestimmt. Für jede Probe werden auf diese Weise mehrere zehntausende 16S-Abschnitte (Reads) sequenziert. Nach bioinformatischer Aufbereitung leitet sich daraus die mikrobielle Zusammensetzung der Probe in Form von Anteilen (relative Abundanzen) einzigartiger AmpliconSequenzvarianten (ASV) ab. Nach einem Datenbankabgleich mit bekannten Sequenzen kann eine taxonomische Zuordnung erfolgen. Mit dieser Methode können zwar keine phänotypischen, metabolischen Charakteristika direkt bestimmt werden, jedoch erlauben vergleichende Analysen verschiedener Proben Rückschlüsse auf die Auswirkungen bestimmter Faktoren auf die mikrobiellen Gemeinschaften (Hou et al. 2018).

Der Prozess der natürlichen Filtration wird bei der Gewinnung von Uferfiltraten angewendet: Durch ufernahe Grundwasserförderung wird eine Potenzialdifferenz der Wasserstände zwischen Oberflächen- und Grundwasser geschaffen, wodurch Oberflächenwasser durch den Untergrund fließt und dabei filtriert wird. Grundwasser wird mit diesem Uferfiltrat angerei- 
chert. Die im Oberflächenwasser vorhandenen Mikroorganismen werden während der Passage teilweise filtriert und aufgehalten, teilweise gelangen sie als allochthone (gebietsfremde) Mikroorganismen in das Grundwasser und verändern dadurch die mikrobielle Gemeinschaft (Hiscock und Grischek 2002). Der Anteil des Uferfiltrats am Grundwasser bestimmt dabei maßgeblich die Veränderung der mikrobiellen Gemeinschaften, d.h. den allochthonen Einfluss. Das bedeutet, dass sich bei einer hohen Potenzialdifferenz zwischen Grundwasser und Flusspegel bewirkt etwa durch hohe Niederschläge einerseits oder große Fördermengen andererseits - der Anteil der mikrobiellen Gemeinschaft aus dem Uferfiltrat erhöht. Gleichzeitig verringert sich die Dauer der Untergrundpassage und damit die Filtrationsleistung, wodurch der Effekt des allochthonen Einflusses verstärkt wird (Grombach et al. 2000).

Vergleichende Analysen mikrobieller Zusammensetzungen verschiedener Uferfiltrate können Hinweise auf den Grad der Oberflächenbeeinflussung liefern und erlauben so Rückschlüsse auf Verteilungsmuster, auf die Dauer der Beeinflussung und Erholung von allochthonen Einträgen. Das Vorhandensein bzw. die Abwesenheit bestimmter Bakteriengruppen kann Hinweise auf die hygienische Qualität und auch auf möglicherweise auftretende technische Probleme liefern. Die Kombination von molekularbiologischen Ansätzen mit robusten quantitativen Methoden zur Bestimmung der Gesamtkonzentration an Zellen vertieft das mikrobiologische Bild beträchtlich. Hier kann die Durchflusszytometrie aufgrund ihrer schnellen und unkomplizierten Untersuchungsmethode sowie der hohen Durchsatzraten und der Möglichkeit zur Online-Messung auch kurzzeitige Veränderungen in der Zellzahl feststellen und so einen Hinweis auf mikrobielle Veränderungen liefern (van Nevel et al. 2017).

\section{Material und Methoden}

\subsection{Untersuchungsort}

Es wurden insgesamt 103 Proben an sechs verschiedenen Uferfiltratstandorten entlang der Donau in Österreich genommen. Insgesamt wurden 18 Brunnen zu verschiedenen Jahreszeiten an jeweils zwei bis fünf Zeitpunkten 2016 und 2017 beprobt (Abb. 1). Einige

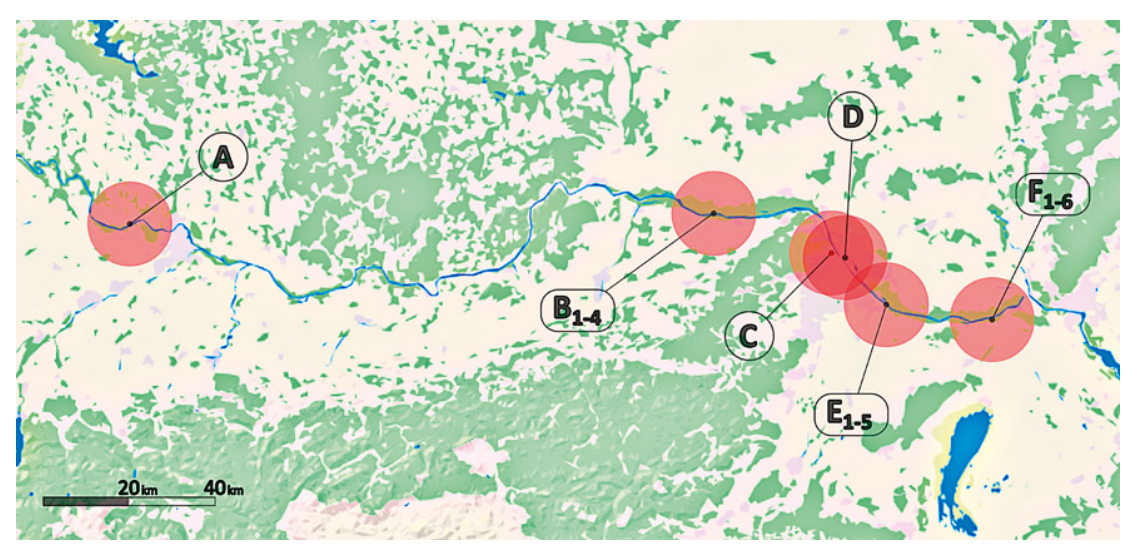

Abb. 1 Karte der Standorte der Brunnenfelder A-F und ihrer Brunnen
Proben wurden in Duplikaten oder Triplikaten beprobt und untersucht, um die Robustheit der Methode zu überprüfen, Details dazu sind in Fiedler et al. (2018) zu finden. Zur besseren Übersicht wurden solche Proben hier gepoolt und jeweils als eine zusammengefasst, sodass 71 Proben ausgewertet wurden.

2016 wurden an 5 Standorten (A-E) mit insgesamt 12 Brunnen je drei Proben genommen: Im Frühling (Februar/ März), im Frühsommer (Mai/Juni) sowie im Herbst (Oktober). Der sechste Standort (F, 6 Brunnen) wurde $2017 \mathrm{im}$ Februar, zweimal im April sowie zweimal im Mai beprobt. Der Standort F wird in dieser Arbeit für eine detailliertere Betrachtung herangezogen. Die Lage der Brunnen relativ zum Fließgewässer bzw. dem Altarm im Augebiet ist in Abb. 2 dargestellt. Der maximale Abstand zum Altarm beträgt etwa $80 \mathrm{~m}$, der minimale etwa $35 \mathrm{~m}$. Bei geringem Wasserstand der Donau führt der Altarm nur sehr wenig Wasser, wodurch sich der Abstand der Brunnen zum nächsten Oberflächengewässer deutlich erhöht. Bei den Brunnen handelt es sich um Vertikalfilterbrunnen mit einer Tiefe zwischen $13 \mathrm{~m}$ und $18 \mathrm{~m}$.

\subsection{Probenahme}

Die Proben für die molekularbiologischen Untersuchungen wurden steril in gemuffelte ( $5 \mathrm{~h}$ bei $550^{\circ} \mathrm{C}$ ), mit Aluminiumfolie verschlossene $5 \mathrm{~L}$-Glasflaschen abgefüllt. Weitere $50 \mathrm{ml}$ wurden zur Zellzahlbestimmung mittels Durchflusszytometrie in sterile Zentrifugenröhrchen abgefüllt. Vor der Entnahme wurden die Probenahmehähne abgeflämmt und das Wasser $10 \mathrm{~min}$ laufen gelassen. Die Proben wurden gekühlt bei $4{ }^{\circ} \mathrm{C}$ transportiert und gelagert und innerhalb von $24 \mathrm{~h}$ verarbeitet. Zusätzlich wurden vor Ort weitere Parameter (Temperatur, Redoxpotenzial, elektrische Leitfähigkeit) gemessen (Fiedler et al. 2018).

\subsection{Probenaufbereitung für Sequenzierung}

Die Probenaufbereitung und Sequenzierung erfolgten wie bei Fiedler et al. (2018) dargelegt. Dabei wurden die

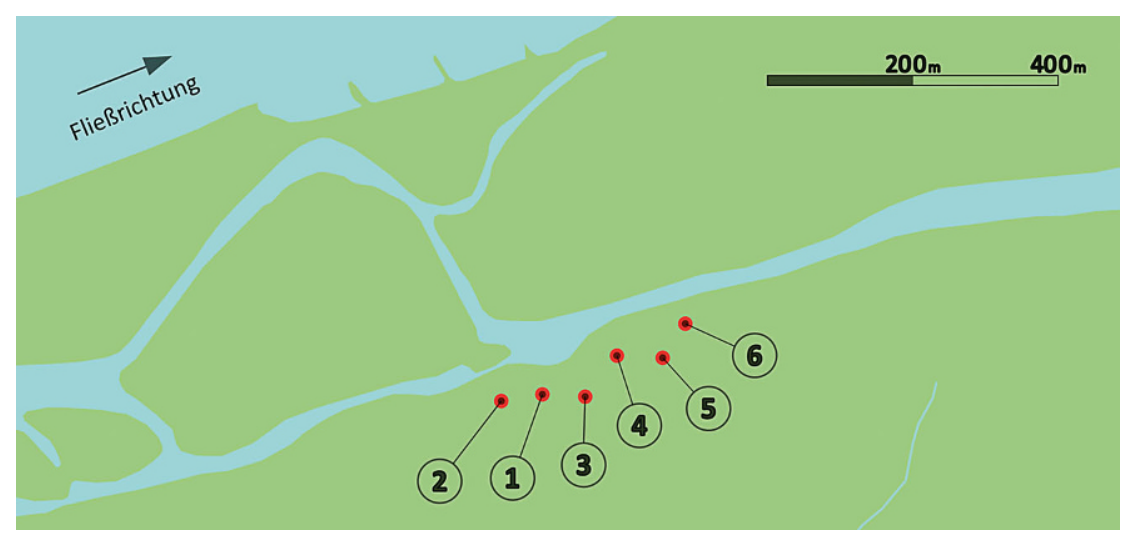

Abb. 2 Lageskizze der einzelnen Brunnen des Standorts F 
Proben über sterile $0,2 \mu \mathrm{m}$ PES-Membranfilter mit einer Wasserstrahlpumpe filtriert, die Filter wurden in Extraktionsröhrchen des DNeasy PowerWater Kits (Qiagen, Deutschland) überführt und mit einem angepassten Protokoll extrahiert. Die DNA-Konzentration wurde fluorometrisch mittels Qubit ${ }^{\circledR}$ dsDNA HS Assay Kit (Invitrogen, OR, USA) bestimmt. Extrahierte DNA wurde bis zur weiteren Verwendung bei $-20^{\circ} \mathrm{C}$ gelagert.

Die PCR wurde in einem zweistufigen Ansatz nach Herbold et al. (2015) durchgeführt. Im ersten Schritt (Amplikon-PCR) wurden die 16S-rRNAAbschnitte mit den Primern S-D-Bact0341-b-S-17 (5' - CCT ACG GGN GGC WGC AG- 3') und S-D-Bact-0785-a-A21 (5' - GAC TAC HVG GGT ATC TAA TCC - 3') amplifiziert. Folgender Ansatz wurde verwendet: 12,5 $\mu \mathrm{l}$ Mastermix (KAPA HiFi Hotstart ready mix, peqlab, Deutschland), jeweils $5 \mu$ l forward und reverse Primer $(2 \mu \mathrm{M})$, sowie $3,5 \mu \mathrm{l}$ extrahierte DNA. Die PCR wurde wie folgt durchgeführt: initiale Denaturierung bei $95^{\circ} \mathrm{C}$ für $5 \mathrm{~min}$, anschließend 32 bis 37 Zyklen Denaturierung bei $95^{\circ} \mathrm{C}, 30 \mathrm{~s}$, Hybridisierung bei $66^{\circ} \mathrm{C}$, $30 \mathrm{~s}$ und Elongation bei $72^{\circ} \mathrm{C}, 30 \mathrm{~s}$ sowie ein finaler Elongationsschritt für 5 min bei $72^{\circ} \mathrm{C}$. Abhängig von der Ausgangs-DNA-Konzentration wurde die Zyklenanzahl angepasst. Um Kontaminationen auszuschließen, wurde bei jeder PCR-Reaktion eine Negativkontrolle mitgeführt. Die PCR-Produkte wurden mit dem peqGOLD cycle-pure Kit (Safety line, peqlab, Deutschland) nach einem modifizierten Protokoll aufgereinigt und anschließend mittels Gelelektrophorese auf ihre Größe und Qualität überprüft sowie die DNA-Konzentration fluorometrisch bestimmt.

Im zweiten Schritt (Index-PCR) wurden Barcodes an die Amplicon-Produkte geheftet, um alle Proben vor der Sequenzierung poolen zu können. Dafür wurden die Primer des Nextera ${ }^{\circledR}$ XT Index Kits v2 (Illumina, CA, USA) verwendet. Für jede Probe wurde eine spezifische Kombination je eines N7xx und S5xx Primers verwendet. Der PCRAnsatz bestand aus je $5 \mu$ l Primer, $25 \mu \mathrm{l}$ Mastermix und $15 \mu \mathrm{l}$ Amplicon-PCRProdukt (normalisiert auf $20 \mathrm{ng}$ ). Die PCR-Bedingungen wurden beibehalten, jedoch mit lediglich sieben Zyklen durchgeführt. Aufreinigung, Gelelektrophorese und Konzentrationsbestimmung wurden wie zuvor durchgeführt.
Alle Proben wurden mit $10 \mathrm{mM}$ TRIS Puffer auf $12 \mathrm{ng} / \mu \mathrm{l}$ verdünnt und $5 \mu \mathrm{l}$ jeder Probe in den finalen Pool pipettiert. Dieser wurde mit der IlluminaMiSeq-Methode sequenziert (Microsynth, Schweiz).

\subsection{Durchflusszytometrie}

Mittels Durchflusszytometrie (Gerät: BD Accuri C6) wurde die Gesamtzellzahl (TCC) bestimmt, die die Konzentration der in einer Wasserprobe vorkommenden Mikroorganismen (Bakterien) beschreibt. Dazu wurden $297 \mu$ l Probe mit $3 \mu l$ des DNA-Farbstoffs $\mathrm{SYBR}^{\circledR}$ Green I versetzt, für $13 \mathrm{~min}$ bei $37^{\circ} \mathrm{C}$ inkubiert und anschließend durchflusszytometrisch gemessen (Zunabovic-Pichler et al. 2018). Die Daten wurden mit der frei zugänglichen Entwicklungsumgebung für statistische Auswertung „R“ bearbeitet (R Core Team 2019), insbesondere mittels des R-Pakets „flowCore“ analysiert (Ellis et al. 2020).

\subsection{Sequenzierungsdaten der Donau}

Für eine vergleichende Analyse der mikrobiellen Zusammensetzung der Uferfiltratproben mit Donauwasser wurden Sequenzierungsdaten (Rohdaten) von Savio et al. (2015) in der gleichen Form aufbereitet wie die eigenen Sequenzierungsergebnisse. Die Probenahme fand 2007 (August/September) im Rahmen des „Joint Danube Survey 2“ statt. Die Sequenzierungsdaten der Donau wurden im Sequence Read Archive des NCBI (National Center for Biotechnology Information) unter der Zugangsnummer SRP045083 zur Verfügung gestellt.

\subsection{Datenauswertung}

Die sequenzierten Rohdaten wurden mit dem R-Paket DADA2 (Callahan et al. 2016) bearbeitet, um sogenannte Amplicon-Sequenzvarianten (ASV) zu erhalten. Die taxonomische Zuordnung erfolgte ebenfalls mit DADA2 (NaiverBayes-Klassifikator) auf Basis der SilvaDatenbank (Yilmaz et al. 2014) mit der Version 138. Die Berechnung eines phylogenetischen Baums zur Abschätzung der Verwandtschaftsgrade zwischen den ASV erfolgte mit der Software QIIME 2 (Bolyen et al. 2019). Ein zusätzliches Clustering von ASV wurde mit VSEARCH (Rognes et al. 2016) durchgeführt. Alle weiteren Datenanalysen basieren auf dem R-Paket phyloseq (McMurdie und Holmes 2013).

Die wichtigsten Methoden zur Datenanalyse umfassen dabei insbesondere Ähnlichkeitsbetrachtungen zur Auffindung von Gruppenbildungen. Hier ist einerseits die PCoA (Principal Coordinates Analysis bzw. multidimensionale Skalierung) zu nennen, andererseits das Dendrogramm auf Basis eines hierarchischen Clusterings (R-Befehl „hclust“ mit der Methode „ward.D2“). Wesentlich ist hier das Distanzmaß, auf dem die Beurteilung der Ähnlichkeit zwischen den Proben basiert. In der vorliegenden Arbeit wurde einerseits eine phylogenetische Distanz (Weighted-Unifrac) verwendet (Lozupone und Knight 2005), die die ASV-Ähnlichkeit einbezieht, andererseits die geläufigere Bray-Curtis-Distanz, die keine Beziehung zwischen den verschiedenen ASV zugrunde legt. Eine weitere Darstellungsform ist die Heatmap, die Proben gegen taxonomische Einheiten in Form einer Matrix aufträgt und Unterschiede in den jeweiligen Abundanzen farblich darstellt. Den Berechnungen liegen stets relative Abundanzen zugrunde.

Das (optional) zusätzliche Clustering von ASV dient der Zusammenfassung von nur sehr gering unterschiedlichen ASV, indem es einen Repräsentanten (die Zentroid-Sequenz) aus einer Gruppe sehr ähnlicher Sequenzen wählt.

\section{Ergebnisse}

\subsection{Vergleich zwischen den Brunnenstandorten}

Die hierarchische Cluster-Analyse auf Basis der Bray-Curtis-Distanz zeigt weitestgehend eine Gruppierung der einzelnen Proben nach den jeweiligen übergeordneten Standorten (Abb. 3). Das bedeutet, dass die Unterschiede in der mikrobiellen Zusammensetzung für Proben eines Standorts geringer sind als zwischen Proben verschiedener Standorte.

Diese Gruppierung ändert sich auch durch eine Zusammenfassung (VSearch-Clustering mit Sequenzähnlichkeit von 97\%) der einzelnen ASV nicht wesentlich, d.h., auch kleinere, möglicherweise standortspezifische Variationen in den ASV sind nicht entscheidend für die Gruppenbildung auf Basis der Bray-Curtis-Distanz (Abb. 4). Das Brunnenfeld $F$ zeigt insgesamt die deutlichsten Unterschiede zu allen anderen Brunnenfeldern, was an der 


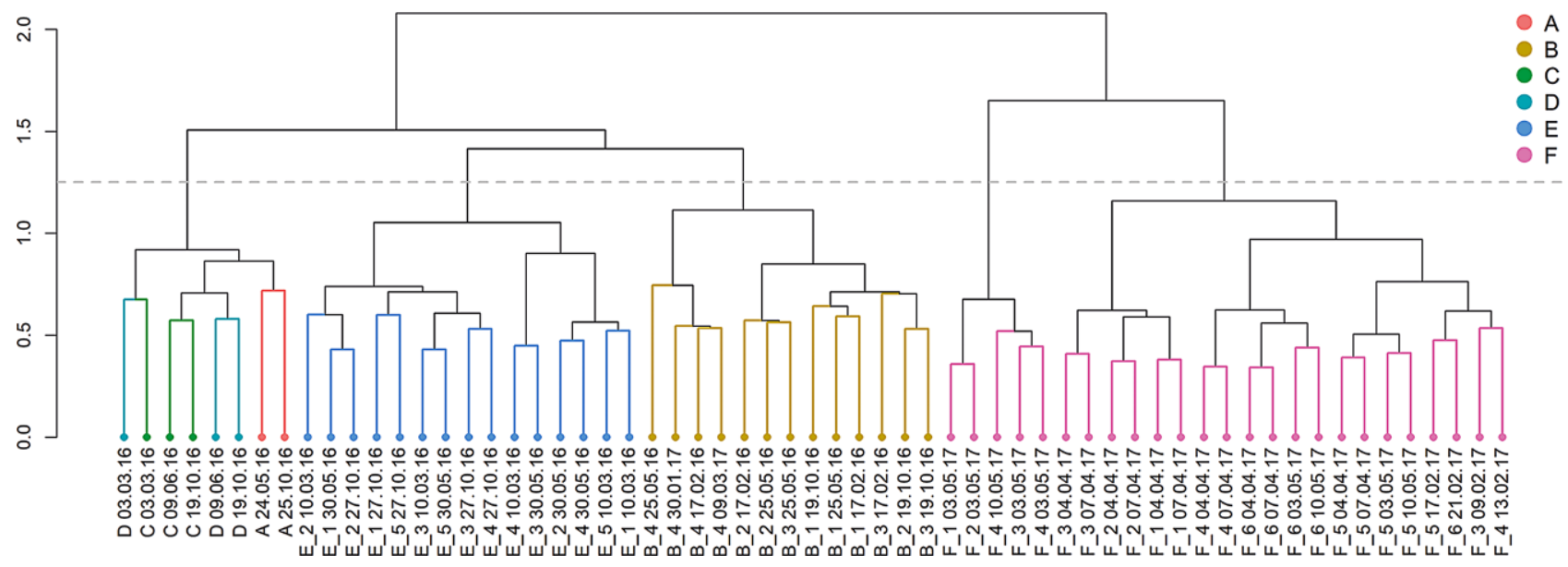

Abb. 3 Hierarchisches agglomeratives Clustering („,hclust“ mit „ward.D2“-Methode auf Basis der Bray-Curtis-Distanz) der einzelnen Proben (relative Abundanzen). Die graue Linie kennzeichnet einen möglichen „Cutoff“ zur Bildung von Gruppen

Hier.-Clustering: ward.D2 (Dist.: bray)

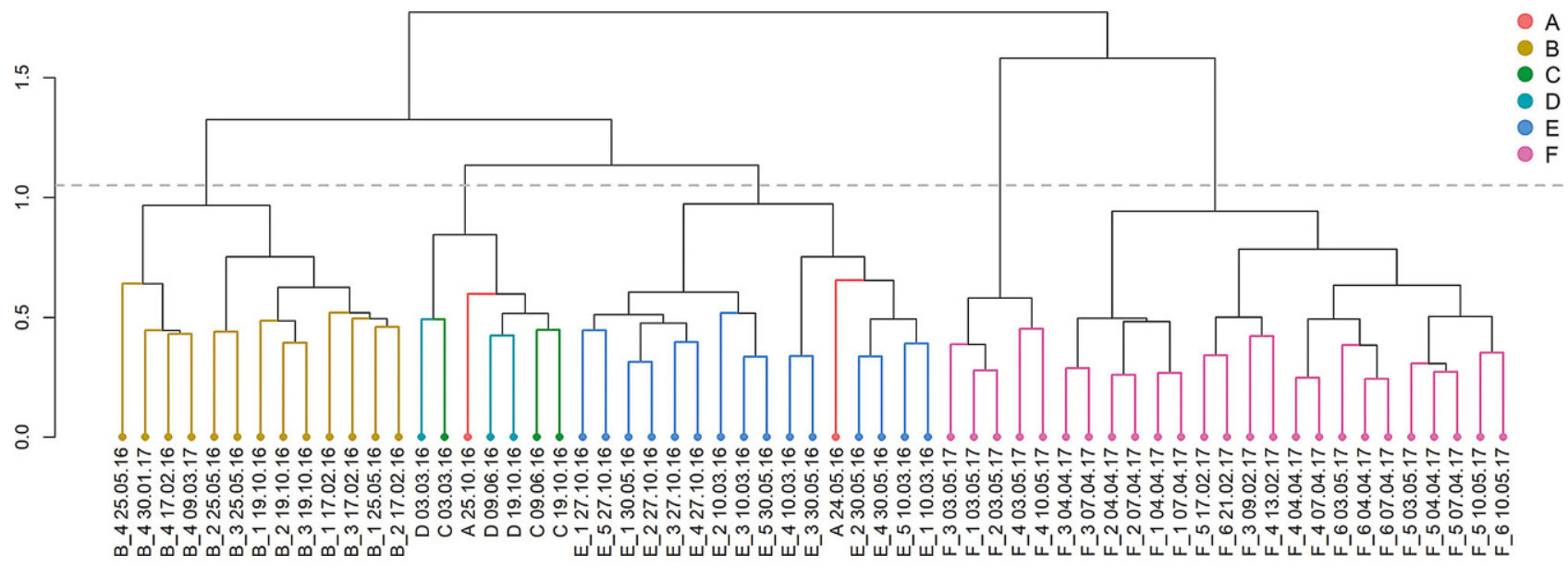

Abb. 4 Hierarchisches agglomeratives Clustering (,hclust“ mit „ward.D2“-Methode auf Basis der Bray-Curtis-Distanz) der einzelnen Proben (relative Abundanzen, 97-\%-Sequenz-Ähnlichkeit). Die graue Linie kennzeichnet einen möglichen Cutoff zur Bildung von Gruppen

Struktur des Dendrogramms ersichtlich ist: Die erste Teilung trennt zwischen dem Standort F und allen anderen. Je nach (subjektiv) festgelegtem Cutoff zur Gruppenbildung (graue Linie) besteht eine gemischte Gruppe zwischen den Standorten A, D und C.

Während hier also eindeutig eine (erwartbare) Gruppierung nach Standort sichtbar wird, besteht bei Verwendung der Weighted-Unifrac-Distanz auch eine Tendenz zur zeitlichen Gruppenbildung (Abb. 5). Hier sind insbesondere die Proben aus dem Frühjahr und Herbst 2016 interessant, da es sich hier um nach Standort gemischte Gruppen handelt.
In Abb. 6 sind zusätzlich zu den Uferfiltrat-Proben auch Proben aus der Donau dargestellt. Es zeigt sich hinsichtlich der Uferfiltrat-Proben ein ähnliches Bild wie etwa in Abb. 4, wenngleich die Gruppierung entlang der Standorte weniger klar hervortritt. Gut zu erkennen sind fünf Proben, deren Zusammensetzung jener der Donauproben mehr zu entsprechen scheint.

Die taxonomische Zusammensetzung der einzelnen Proben auf PhylumEbene ist in Abb. 7 dargestellt. Hier zeigt sich insgesamt eine eindeutige Dominanz einiger Phyla (Verrucomicrobiota, Planctomycetota, Patescibacteria und Acidobacteriota). An standortspezifi- schen Unterschieden ist etwa der höhere Anteil an Verrucomicrobiota am Standort E zu nennen.

Die folgende Heatmap-Darstellung (Abb. 8) der relativen Abundanzen (wiederum Phylum-Ebene) dient der visuellen Erfassung von Gemeinsamkeiten zwischen Proben (horizontale Achse) bzw. taxonomischen Einheiten (vertikale Achse). Normalerweise werden die Zeilen und Spalten mithilfe einer Ordinations-Methode (etwa der multidimensionalen Skalierung) nach Ähnlichkeit zueinander gruppiert, hier allerdings erfolgt die Anordnung nach Standort (horizontale Achse) bzw. Häufigkeit des Auftretens (vertikale Achse). 
Hier.-Clustering: ward.D2 (Dist.: wunifrac)

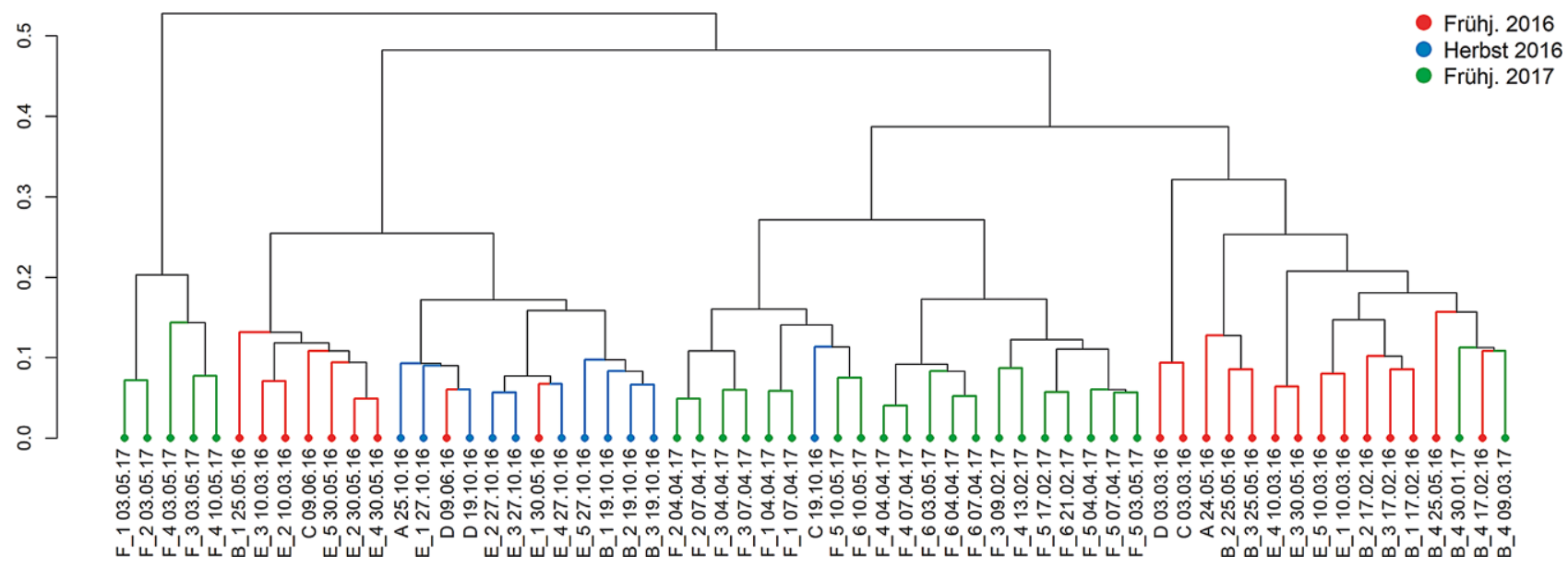

Abb. 5 Hierarchisches agglomeratives Clustering (,hclust“ mit „ward.D2“-Methode auf Basis der Weighted-Unifrac-Distanz) der einzelnen Proben (relative Abundanzen)

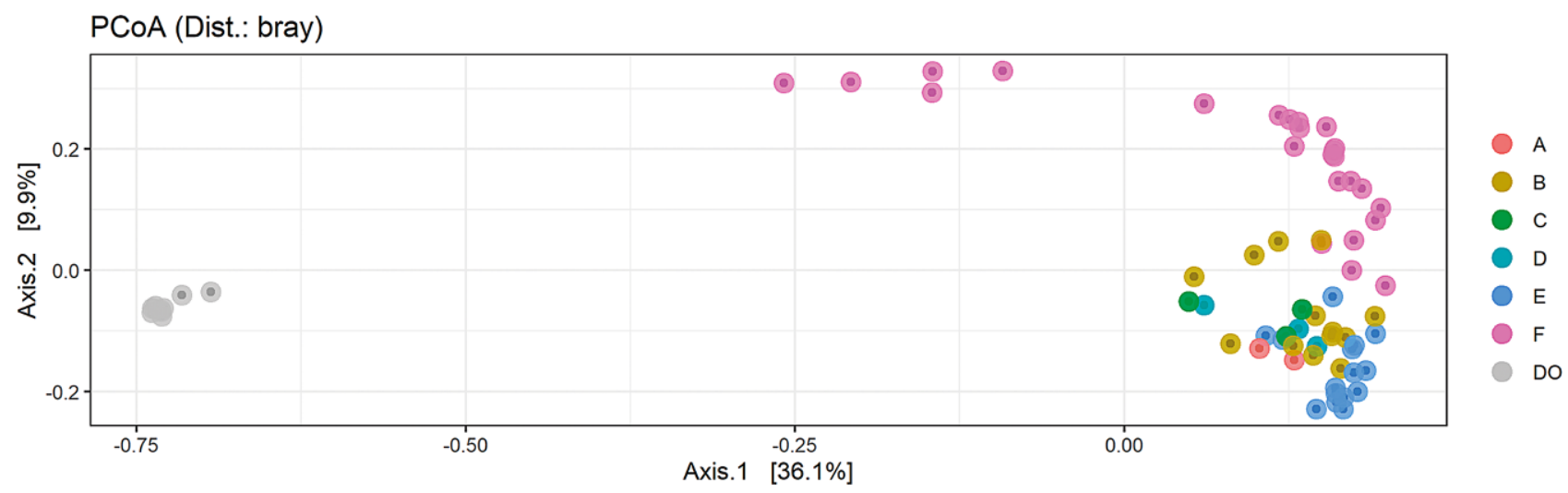

Abb. 6 PCoA-Darstellung (Bray-Curtis-Distanz) der einzelnen Proben (relative Abundanzen, 97-\%-Sequenz-Ähnlichkeit)

Dunkle Bereiche bedeuten ein verstärktes Vorkommen. Es zeigt sich hinsichtlich der Zusammensetzung der Uferfiltrat-Proben ein im Großen und Ganzen recht homogenes Bild, das sich deutlich von den Donau-Proben unterscheidet. Eine interessante Beobachtung betrifft allerdings einige Uferfiltrat-Proben aus dem Standort F, die sich deutlicher von den restlichen Uferfiltrat-Proben unterscheiden und eher Eigenschaften der Donauproben aufweisen. Dies betrifft dabei insbesondere die Phyla Actinobacteriota, Bacteroidota, Cyanobacteria und Armatimonadota.

\subsection{Detailbetrachtung von Brunnenfeld $\mathrm{F}$}

Aufgrund der hohen Probenanzahl (25) und der etwa in Abb. 6 und 8 gezeigten Besonderheiten einiger der Proben die- ses Standorts soll dieser im Folgenden näher betrachtet werden.

\subsubsection{Hydrologie und Brunnenbetrieb}

Aufgrund eines Niederschlagsereignisses im Mai 2017 kam es zu einem erhöhten Wasserstand in der Donau und insbesondere im unmittelbar an die Brunnen angrenzenden Altarm (Abb. 9). Aber auch schon bei der Probenahme am 3. Mai bestand eine Situation mit einem deutlich erhöhten Wasserstand relativ zu den vorangegangen Probenahmen Anfang April und im Februar.

Die Förderraten der einzelnen Brunnen sind in Abb. 10 dargestellt. Von betrieblicher Seite ist insbesondere für die Probenahmen im April und im Mai nur wenig Unterschied auszumachen, da in beiden Fällen eine kontinuierliche Förderung bestand. Für die Probenahmen im Februar, bei denen nacheinander die Brunnen 3 bis 6 beprobt wurden, ist zwar ebenfalls stets eine Förderung vorhanden, allerdings mit geringerer Vorlaufzeit.

\subsubsection{Chemisch-physikalische Parameter}

Untersuchungen aus dem Frühjahr 2017 zeigen trotz der räumlichen Nähe der Brunnen zueinander eine deutlich abweichende Zusammensetzung des Brunnens 5. Sowohl die Gesamthärte bzw. die elektrische Leitfähigkeit als auch der Nitrat-Gehalt sind im Vergleich zu den anderen Brunnen deutlich erhöht. So liegt die elektrische Leitfähigkeit (bei $25^{\circ} \mathrm{C}$ ) Anfang April für die Brunnen 1 bis 4 und 6 im Bereich zwischen 550 und $700 \mu \mathrm{S} / \mathrm{cm}$, aber im Brunnen 5 deutlich über $900 \mu \mathrm{S} / \mathrm{cm}$. Gleichermaßen liegt der Nitrat-Gehalt zu diesem Zeitpunkt in den Brunnen 1 


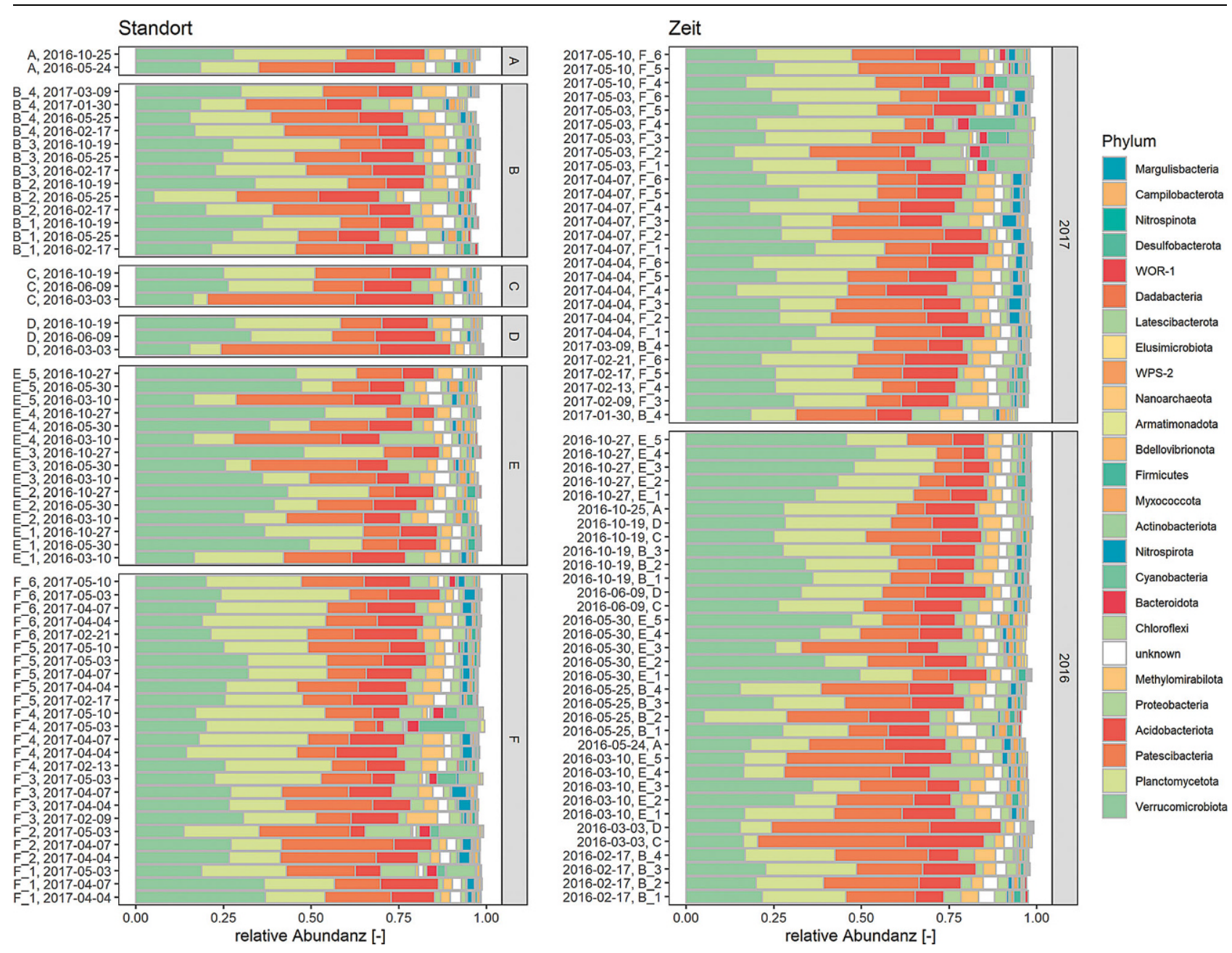

Abb. 7 Relative Abundanzen der häufigsten Phyla angeordnet nach Standort bzw. zeitlicher Abfolge der Probenahmen

Phylum

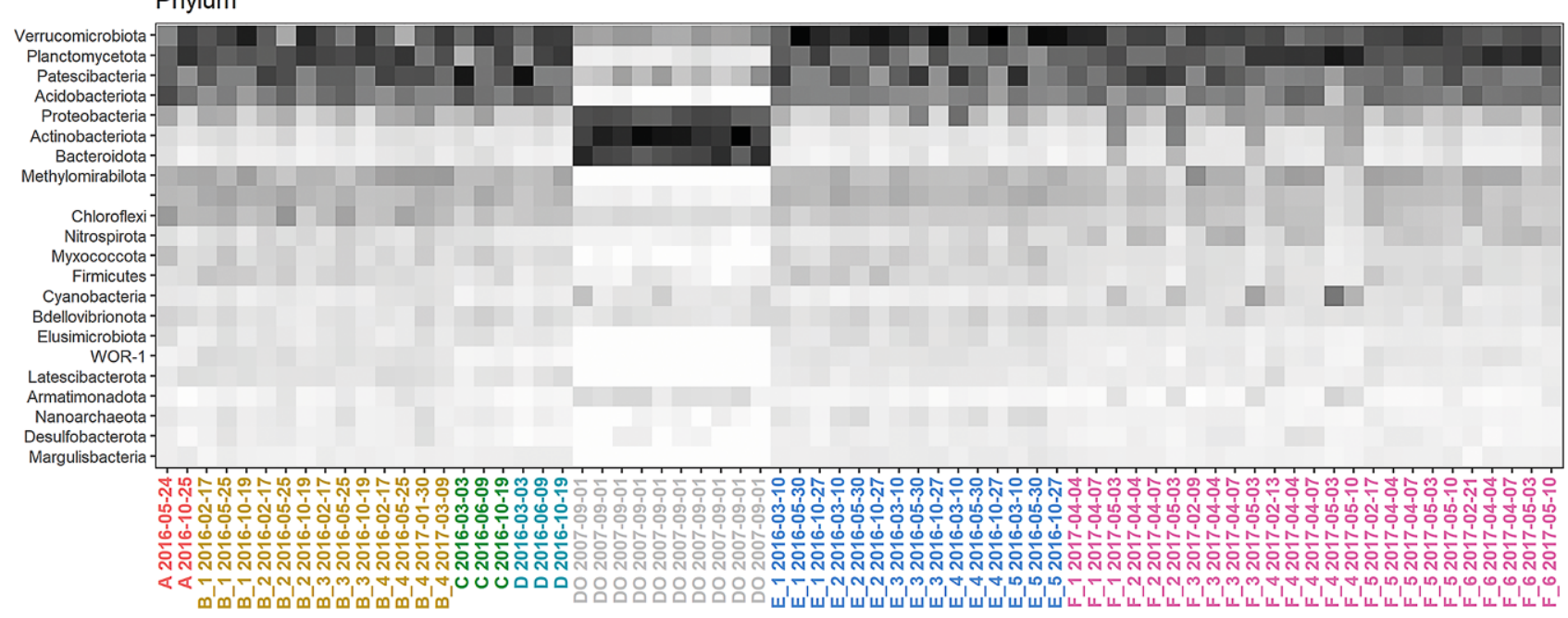

Abb. 8 Heatmap-Darstellung der relativen Abundanzen aufPhylum-Ebene unter Einbeziehung der Proben aus der Donau. Je dunkler der Bereich, desto höher die relative Abundanz 
Hier steht eine Anzeige.

Springer 
Hier steht eine Anzeige.

Springer 


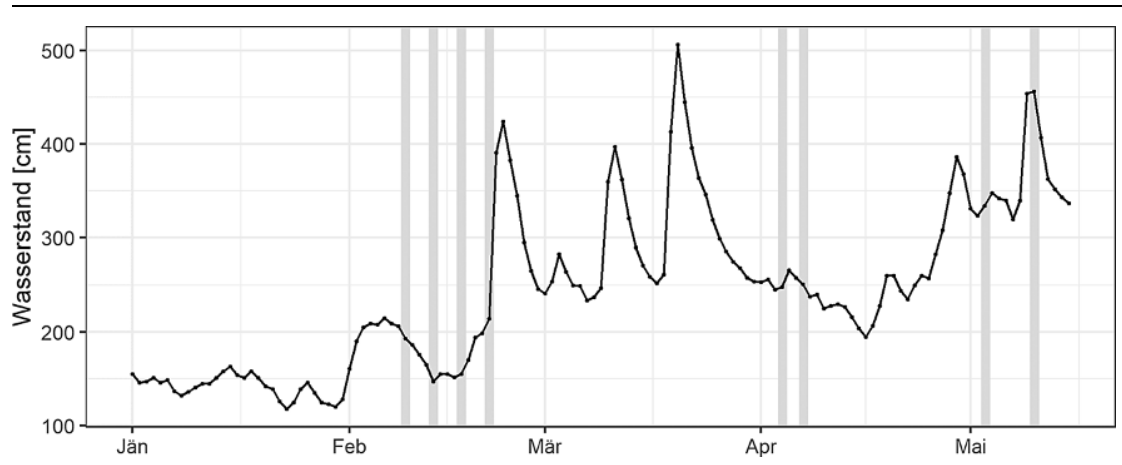

Abb. 9 Wasserstandsganglinie der Donau mit Probenahmezeitpunkten

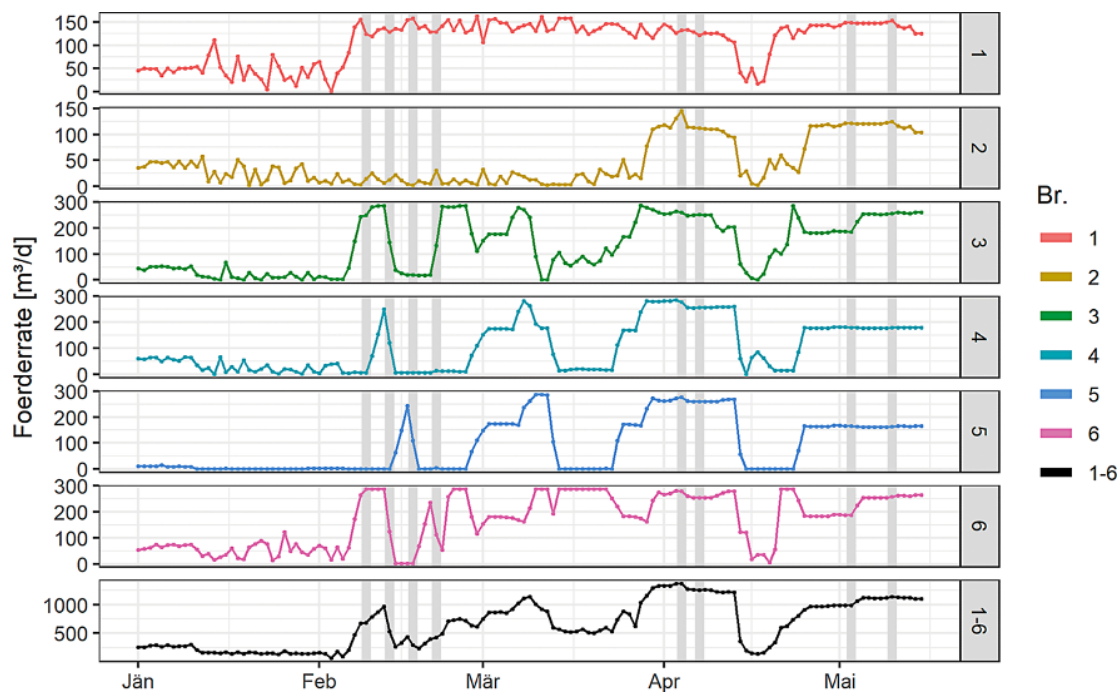

Abb. 10 Ganglinie der Förderraten der einzelnen Brunnen und deren Summe. Grau die Probenahmezeitpunkte

bis 4 und 6 im Bereich von etwa $5 \mathrm{mg} / \mathrm{l}$, im Brunnen 5 bei über $25 \mathrm{mg} / \mathrm{l}$. Der TOC als Maß für den Organik-Gehalt (im Bereich zwischen 0,9 und 1,5 mg/l) und die Temperatur (im Bereich von $12^{\circ} \mathrm{C}$ und $15^{\circ} \mathrm{C}$ ) zeigen Anfang April keine besonders augenscheinlichen Unterschiede zwischen den Brunnen. Auch bei anderen Probenahmen tritt die Unterschiedlichkeit des Brunnens 5 hervor. Es ist daher davon auszugehen, dass hier eine besondere hydrogeologische Situation vorliegt und ein stärkerer landseitiger Einfluss wirkt.

Die Untersuchungen vom Anfang des Monats Mai zeigen eine Abnahme der elektrischen Leitfähigkeit (und der Wasserhärte) bei den meisten Brunnen, mit einer eher geringen Änderung bei Brunnen 4 und einer starken Änderung bei Brunnen 5. In Brunnen 5 ist auch ein deutlicher Rückgang der Nitratkonzentration zu verzeichnen. Diese beträgt am 10. Mai nur noch $10 \mathrm{mg} / \mathrm{l}$. Der Organikgehalt zeigt lediglich eine beschriebene Gruppenbildung wohl noch vorhanden, da sich der Brunnen 4 wiederum eher getrennt positioniert. Die Probenahme am 10. Mai zeigt schließlich, dass Brunnen 5 und 6 nun ebenfalls eine Veränderung ihrer mikrobiellen Zusammensetzung erfahren haben.

Das Dendrogramm in Abb. 12 zeigt Ergebnisse für zwei Distanzmaße, einerseits die Bray-Curtis-Distanz (wie in der PCoA), andererseits die WeightedUnifrac-Distanz. Im Fall von letzterer tritt die besagte Gruppenbildung im April deutlich weniger stark hervor. Insgesamt beruhen die Unterschiede zwischen den Proben wohl eher auf zeitlichen Entwicklungen, denn auf räumlichen Eigenheiten der einzelnen Brunnen.

Die durchflusszytometrischen Gesamtzellzahlen (TCC) liegen für die Probenahmen Anfang April in einem für Uferfiltrate nicht ungewöhnlichen Bereich von knapp 150.000 bis maximal 300.000 Zellen/ml (Zunabovic-Pichler et al. 2018). Dabei weist Brunnen 1 die geringsten und Brunnen 4 die höchsten Werte auf. Die Probenahme vom 3. Mai zeigt einen starken Anstieg der TCC für die Brunnen 1 bis 4 auf maximal 600.000 Zellen/ml (Brunnen 2), während die Brunnen 5 und 6 konstante Werte zeigen. Am 10. Mai ist ein deutlicher Abfall der TCC der Brunnen 1 und $2 \mathrm{zu}$ verzeichnen, während sich der Anstieg für die Brunnen 3 und 4 fortsetzt. Brunnen 6 zeigt nun ebenfalls eine Zunahme, aber Brunnen 5 ist weiterhin konstant. Insgesamt deuten diese Ergebnisse auf eine relativ geringe Beeinflussung der Gesamtanzahl an Bakterien für die Brunnen 6 sowie insbesondere 5 hin. Diese Beobachtung deckt sich auch mit den Ergebnissen der Ähnlichkeitsbetrachtung der Sequenzierungsergebnisse (Abb. 11).

In der PCoA-Darstellung und dem Dendrogramm zur Veranschaulichung der Ähnlichkeiten zwischen den Proben lassen sich nun einige interessante Punkte beobachten (Abb. 11 und 12). Die Proben aus dem Februar weisen insgesamt eine große Ähnlichkeit zueinander auf, während sich im April tendenziell zwei Gruppen abzeichnen (Brunnen 1 bis 3 und 4 bis 6 ). Aufgrund des recht kurzen Abstands der Probenahmen im April gruppieren sich die Proben für die jeweiligen Brunnen nahe beieinander. Die Probenahme am 3. Mai zeigt erstmals eine deutliche Unterschiedlichkeit für die Brunnen 1 bis 4 relativ zu den bisherigen Proben. Auch hier ist die

\subsection{Vergleich der Amplicon- Sequenzvarianten von Uferfiltrat und Donau}

Ein Vergleich des Mikrobioms im Uferfiltrat mit dem Mikrobiom des Donauwassers zeigt zunächst eine deutliche Abgrenzung beider Wassertypen voneinander (Abb. 6 und 8), wie sie aufgrund der unterschiedlichen Umweltbedingungen auch zu erwarten ist. In besagten Abbildungen ist dennoch bereits eine Annäherung einiger Proben des Standorts F an die Proben aus der Donau ersichtlich. Insbesondere aus 


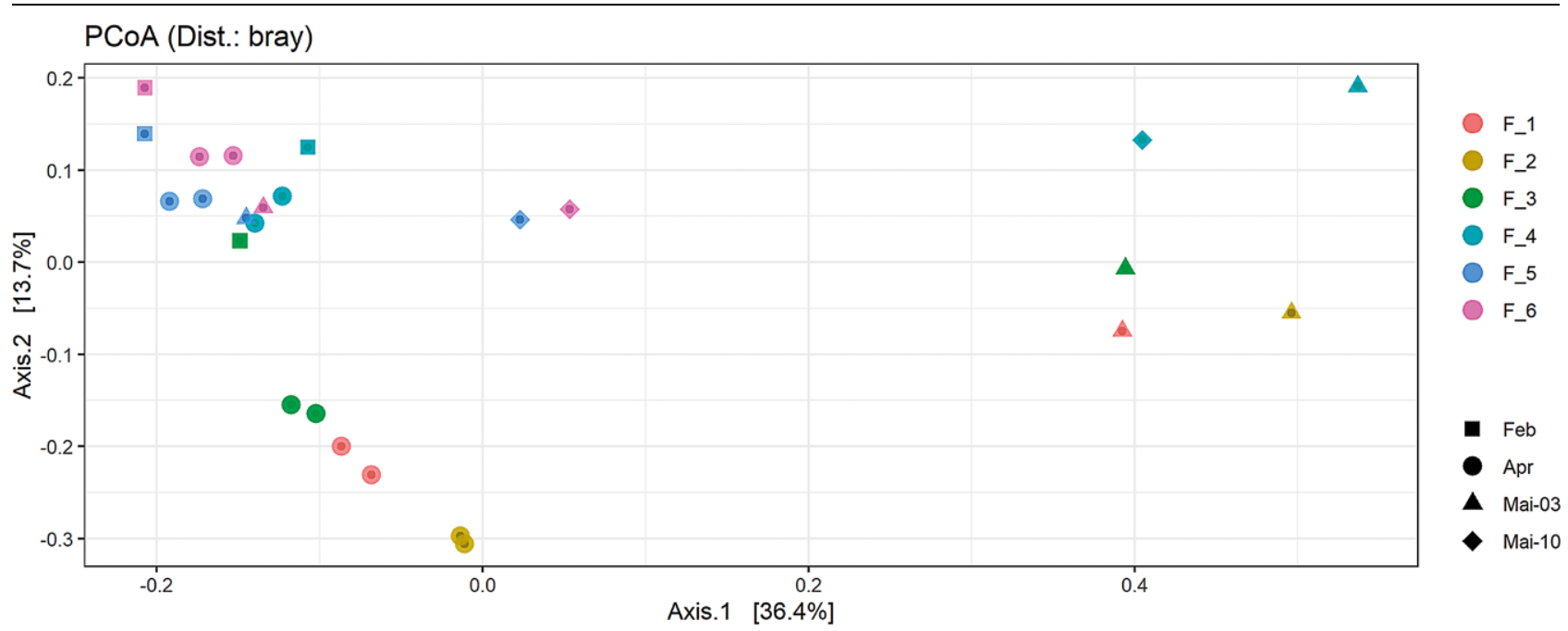

Abb. 11 PCoA-Darstellung (Bray-Curtis-Distanz) der einzelnen Proben (relative Abundanzen, 97-\%-Sequenz-Ähnlichkeit)

Hier.-Clustering: ward.D2 (Dist.: bray)

Hier.-Clustering: ward.D2 (Dist.: wunifrac)
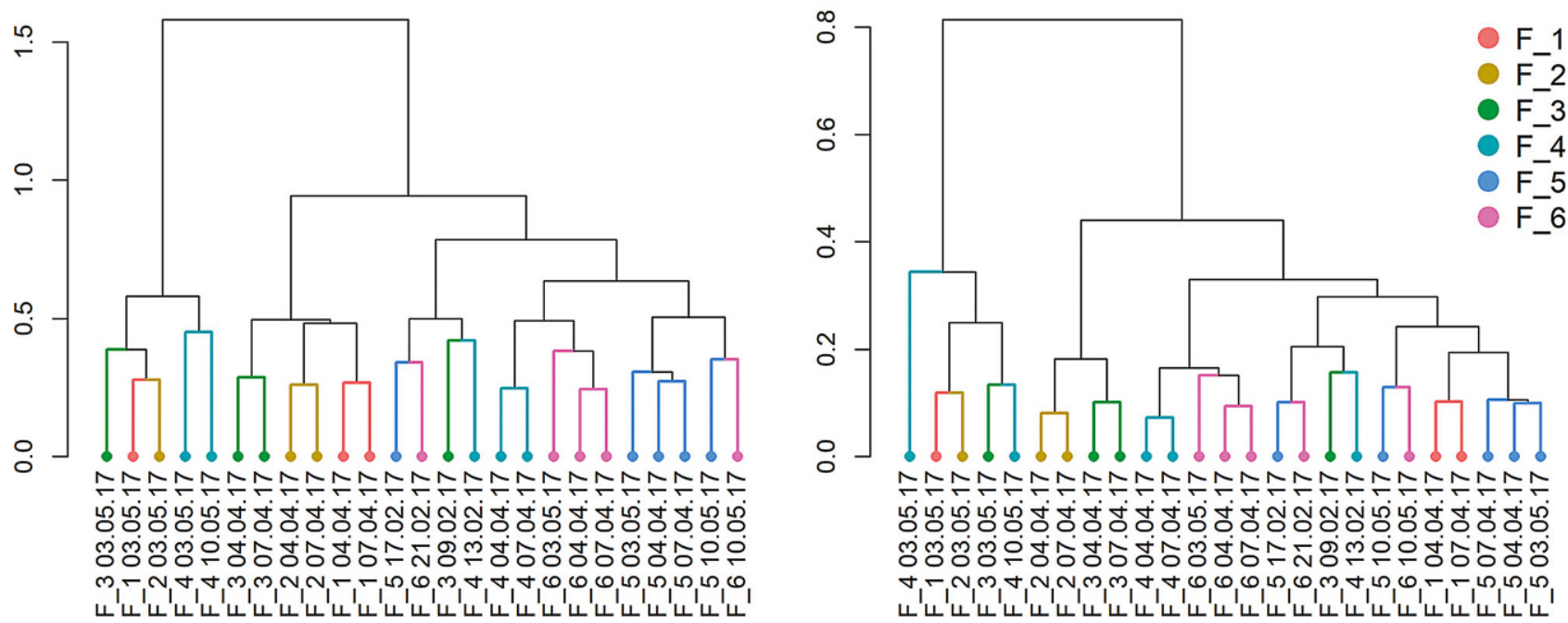

Abb. 12 Hierarchisches agglomeratives Clustering (,hclust“ mit „ward.D2“-Methode auf Basis der Bray-Curtis-Distanz bzw. der Weighted-Unifrac-Distanz) der einzelnen Proben (relative Abundanzen)

Abb. 6 ergibt sich, dass einige der ASV in beiden Gruppen übereinstimmen. Abb. 13 zeigt nun, welcher Anteil an der Gesamtanzahl der Reads in den einzelnen Proben auf jene ASV entfällt, die in beiden Gruppen vorhanden sind. Hier werden für einige Proben überraschend hohe Anteile erreicht.

In den sieben Proben des Standortes F mit einem erhöhten Anteil an gemeinsamen ASV entfallen $10 \%$ aller Reads auf eine einzige ASV. Diese Sequenzvariante ist in der Donau selbst allerdings nicht im gleichen Ausmaß dominant, sondern ist im Gegenteil eher selten. Die Klassifizierung auf Basis der Silva-Datenbank ordnet die Se- quenz dem Phylum Planctomycetota und der Familie der Isosphaeraceae zu. Eine Online-Abfrage der Sequenz bei der Nucleotide Collection des NCBI ergibt 13 Treffer mit 100\% Übereinstimmung, die acht verschiedenen Studien (China, USA, Kanada und Schweiz) zugeordnet sind (NCBI 2018). Aus den Titeln der Studien wird durchgehend ersichtlich, dass eine Verbindung zu stehenden Oberflächengewässern besteht. Wenngleich dies nicht zwingend bedeutet, dass tatsächlich ein bedeutender Eintrag von Mikroorganismen aus dem Oberflächengewässer - wohl aus dem Altarm - stattgefunden hat, so ist es doch als starkes Indiz dafür zu werten.

\section{Diskussion}

Um einen Überblick über räumliche und zeitliche Veränderungen und $\mathrm{Ab}$ hängigkeiten des Mikrobioms in verschiedenen Uferfiltraten in Österreich zu erhalten, wurden entlang der Donau sechs Uferfiltratstandorte mit insgesamt 18 Brunnen untersucht (Abb. 1). Dabei zeigt sich insgesamt eine räumliche Trennung der sechs Standorte, insbesondere die Standorte B und F sind klar von den übrigen abzugrenzen (Abb. 3). Die räumliche Nähe der Brun- 


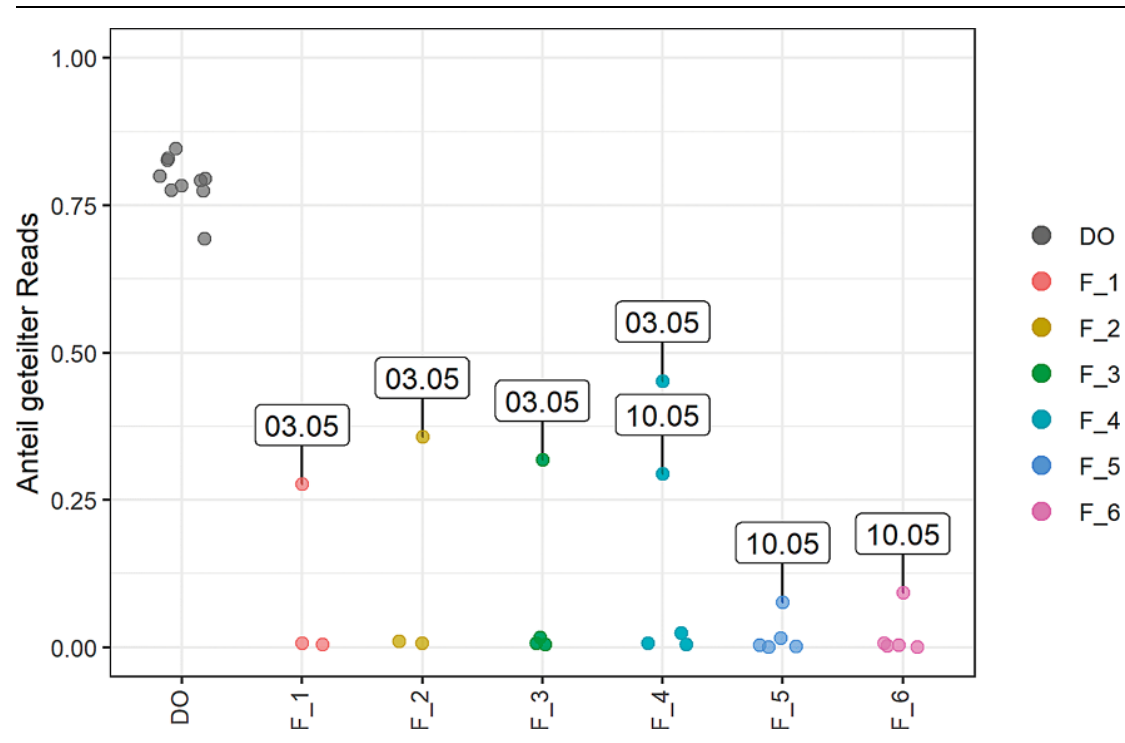

Abb. 13 Anteil der Reads einer Probe, die aus gemeinsamen Amplicon-Sequenzvarianten stammen

nenfelder $\mathrm{C}$ und $\mathrm{D}$ zueinander sowie standortspezifische Eigenheiten (relativ nahe Positionierung an der Donau) können hier als Erklärung für deren Ähnlichkeit dienen. Brunnenfeld A befindet sich in deutlicher Entfernung von den anderen Standorten, unterscheidet sich insgesamt aber nicht in besonderem Ausmaß von den anderen. Je nach Standort können auch sehr kleinräumige hydrogeologische Unterschiede Bedeutung gewinnen, wie etwa im Brunnenfeld $F$ ersichtlich, wo die Abstände zwischen den Brunnen nur etwa $50 \mathrm{~m}$ betragen (Abb. 12). Hier lassen sich die Brunnen 1 bis 3 gut von den Brunnen 4 bis 6 abgrenzen (Abb. 11). Darüber hinaus weist Brunnen 5, der am weitesten vom Oberflächengewässer entfernt ist, eine deutlich unterschiedliche chemische Zusammensetzung auf. Wenngleich sich diese chemische Unterschiedlichkeit nicht in der mikrobiologischen Zusammensetzung widerspiegelt, so ist hier die Beeinflussung durch das Oberflächenwasser (den Altarm) für diesen Brunnen wohl am geringsten. Die Dauer der Bodenpassage nimmt großen Einfluss auf die Zusammensetzung der Mikroorganismen.

Im jahreszeitlichen Verlauf zeigen sich weniger starke Unterschiede in der Zusammensetzung der Mikrobiome, wenngleich sich eine zeitliche Gruppierung zumindest andeutet (Abb. 5). Durch den Temperaturgang und andere abiotische Faktoren, die sich saisonal verändern, können bestimmte hier eine bloße Änderung der Umgebungsbedingungen im Untergrund die Ursache ist. Die chemisch-physikalischen Parameter deuten auch nicht auf einen dramatischen Wechsel hin. Das Ausbleiben einer deutlichen Änderung dieser Parameter, etwa der Temperatur oder der Leitfähigkeit, bei vermutetem Oberflächenwassereinfluss mag auf eine jahreszeitlich bedingte Ähnlichkeit zwischen Grund- und Oberflächenwasser zurückzuführen sein. Die bei erhöhtem Wasserstand zu verzeichnende deutliche Zunahme der Gesamtzellzahl kann ebenso mit einem allochthonen Eintrag erklärt werden. Auch wenn der Anteil an Oberflächenwasser nur gering sein sollte, ist durch die wesentlich höhere Zelldichte im Oberflächengewässer eine stärkere Beeinflussung des mikrobiologischen Zustandes rasch erreicht.

Zusammenfassend lässt sich sagen, dass mit der Bestimmung der taxonomischen Zusammensetzung (Mikrobiom) durch das High-Throughput-Sequencing ein äußerst sensitives Werkzeug zur Beschreibung des mikrobiologischen Zustands von Wasserproben zur Verfügung steht. Wie dargelegt wurde, ist es möglich, die Resultate von zeitlich deutlich auseinanderliegenden Untersuchungen sinnvoll $\mathrm{zu}$ vergleichen und daraus neue Erkenntnisse zu gewinnen. Hier konnte etwa ein sehr starkes Indiz für den direkten (mikrobiologischen) Einfluss von Oberflächenwasser in die Gewinnungsstellen gewonnen werden. Ein Schwerpunkt dieser Arbeit bestand hauptsächlich in der (bloßen) Betrachtung von Ähnlichkeiten zwischen Proben mittels bioinformatischer Hilfsmittel. Damit verbleibt insbesondere die ökologische Interpretation, die sich mit den Funktionen der mikrobiologischen $\mathrm{Ge}$ meinschaft beschäftigt, als zukünftige Herausforderung.

Funding Open access funding provided by University of Natural Resources and Life Sciences Vienna (BOKU).

\section{Interessenkonflikt}

C. J. Fiedler, C. Schönher, P. Proksch, D. J. Kerschbaumer, E. Mayr, M. Zunabovic-Pichler und R. Perfler geben an, dass kein Interessenkonflikt besteht.

Open Access Dieser Artikel wird unter der Creative Commons Namensnennung 4.0 International Lizenz veröffent- 
licht, welche die Nutzung, Vervielfältigung, Bearbeitung, Verbreitung und Wiedergabe in jeglichem Medium und Format erlaubt, sofern Sie den/die ursprünglichen Autor(en) und die Quelle ordnungsgemäß nennen, einen Link zur Creative Commons Lizenz beifügen und angeben, ob Änderungen vorgenommen wurden.
Die in diesem Artikel enthaltenen Bilder und sonstiges Drittmaterial unterliegen ebenfalls der genannten Creative Commons Lizenz, sofern sich aus der Abbildungslegende nichts anderes ergibt. Sofern das betreffende Material nicht unter der genannten Creative Commons Lizenz steht und die betreffende Handlung nicht nach gesetzlichen
Vorschriften erlaubt ist, ist für die oben aufgeführten Weiterverwendungen des Materials die Einwilligung des jeweiligen Rechteinhabers einzuholen.

Weitere Details zur Lizenz entnehmen Sie bitte der Lizenzinformation auf http://creativecommons.org/licenses/ by/4.0/deed.de.

Literatur

Bannick, C., B. Engelmann, R. Fendler, J. Frauenstein, H. Ginsky, C. Hornemann, O. Ilvonen, B. Kirschbaum, G. Penn-Bressel, J. Rechenberg, S. Richter, L. Roy \& R. Wolter (2008): Grundwasser in Deutschland. 72. Berlin: Bundesministerium für Umwelt, Naturschutz und Reaktorsicherheit (BMU).

Bolyen, Evan, Jai Ram Rideout, Matthew R. Dillon, Nicholas A. Bokulich, Christian C. Abnet, Gabriel A. Al-Ghalith, Harriet Alexander et al. (2019): Reproducible, Interactive, Scalable and Extensible Microbiome Data Science Using QIIME 2. Nature Biotechnology 37 (8): 852-57. Callahan, Benjamin J, Paul J McMurdie, Michael J Rosen, Andrew W Han, Amy Jo A Johnson, und Susan P Holmes (2016): DADA2: High resolution sample inference from Illumina amplicon data. Nature methods 13 (7): 581-83.

Danielopol, D. L., C. Griebler, A. Gunatilaka \& J. Notenboom (2003): Present state and future prospects for groundwater ecosystems. Environmental Conservation, 30, 104-130.

Ellis B, Haaland P, Hahne F, Le Meur N, Gopalakrishnan N, Spidlen J, Jiang M, Finak G (2020): flowCore: Basic structures for flow cytometry data. $R$ package version 2.0.1.

Fiedler, C. J., C. Schönher, P Proksch, D. J. Kerschbaumer, E. Mayr, M. Zunabovic-Pichler, K. J. Domig \& R. Perfler (2018): Assessment of microbial community dynamics in river bank filtrate using high-throughput sequencing and flow cytometry. Frontiers in Microbiology. https://doi.org/10.3389/fmicb.2018.02887. Griebler, C. \& T. Lueders (2009): Microbia biodiversity in groundwater ecosystems. Freshwater Biology, 54, 649-677.

Grombach, P., H. Haberer, G. Merkl \& E. U. Trüeb (2000): Handbuch der Wasserversorgung. München: Oldenbourg Industrieverlag.

Herbold, C. W., C. Pelikan, O. Kuzyk, B. Hausmann, R. Angel, D. Berry \& A. Loy (2015): A flexible and economical barcoding approach for highly multiplexed amplicon sequencing of diverse target genes. Frontiers in Microbiology, 6,731
Hiscock, K. M. \& T. Grischek (2002): Attenuation of groundwater pollution by bank filtration. Journal of Hydrology, 266, 139-144.

Hou, L., Q. Zhou, Q. Wu, Q. Gu, M. Sun \& J. Zhang (2018): Spatiotemporal changes in bacterial community and microbial activity in a fullscale drinking water treatment plant. Science of the Total Environment, 625, 449-459.

Iliev, I., G. Yahubyan, M. Marhova, E. Apostolova, M. Gozmanova, G. Gecheva, S. Kostadinova, A. Ivanova \& V. Baev (2017): Metagenomic profiling of the microbial freshwater communities in two Bulgarian reservoirs. Journal of Basic Microbiology, 57, 669-679.

Karczewski, K., H. W. Riss \& E. I. Meyer (2017) Comparison of DNA-fingerprinting (T-RFLP) and high-throughput sequencing (HTS) to assess the diversity and composition of microbial communities in groundwater ecosystems. Limnologica-Ecology and Management of Inland Waters, 67, 45-53.

Kim, H., D. Kaown, B. Mayer, J. Y. Lee \& K. K. Lee (2018): Combining pyrosequencing and isotopic approaches to assess denitrification in a hyporheic zone. Science of the Total Environment 631-632, 755-764.

Lozupone, Catherine, und Rob Knight (2005): UniFrac: A New Phylogenetic Method for Comparing Microbial Communities. Applied and Environmental Microbiology 71 (12): 8228-35.

McMurdie, Paul J., und Susan Holmes (2013): phyloseq: An R Package for Reproducible Interactive Analysis and Graphics of Microbiome Census Data. PLOS ONE 8 (4): e61217.

NCBI (2018): Database resources of the National Center for Biotechnology Information. Nucleic Acids Research 46 (Database issue): D8-13.

van Nevel, S., S. Koetzsch, C. R. Proctor, M. D. Besmer, E. I. Prest, J. S. Vrouwenvelder, A. Knezev, N. Boon \& F. Hammes (2017): Flow cytometric bacterial cell counts challenge conventional heterotrophic plate counts for routine microbiological drinking water monitoring. Water Research, 113, 191-206.
Newton, R. J., S. E. Jones, A. Eiler, K. D. McMahon \& S. Bertilsson (2011): A guide to the natura history of freshwater lake bacteria. Microbiology and Molecular Biology Reviews, 75, 14-49. Pedersen, K. (2000): Exploration of deep intraterrestrial microbial life: Current perspectives. FEMS Microbiology Letters, 185, 9-16.

R Core Team (2019): R: A language and environment for statistical computing. R Foundation for Statistical Computing, Vienna, Austria. URL https://www.R-project.org/

Raes, J. \& P. Bork (2008): Molecular ecosystems biology: towards an understanding of community function. Nature Reviews Microbiology, 6, 693 Rognes, Torbjørn, Tomáš Flouri, Ben Nichols, Christopher Quince, und Frédéric Mahé (2016) VSEARCH: a versatile open source tool for metagenomics. PeerJ. https://doi.org/10.7717/peerj. 2584 .

Savio, D., L. Sinclair, U. Z. Ijaz, J. Parajka, G. H. Reischer, P. Stadler, A. P. Blaschke, G. Blöschl, R. L. Mach, A. K. T. Kirschner, A. H. Farnleitner \& A. Eiler (2015): Bacterial diversity along a $2600 \mathrm{~km}$ river continuum. Environmental Microbiology, 17, 4994-5007.

Yilmaz, P., L. Wegener Parfrey, P. Yarza, J. Gerken, E. Pruesse, C. Quast, T. Schweer, J. Peplies, W. Ludwig, F. O. Glöckner (2014): The SILVA and "All-Species Living Tree Project (LTP) Taxonomic Frameworks". Nucleic Acids Research 42 (D1): D643-48.

Zunabovic-Pichler, M., E. Mayr, C. Schönher, C. Fiedler, D. Kerschbaumer, P. Proksch, R. Perfler (2018): Durchflusszytometrie in der Wasserversorgung. Mikrobiologische Charakterisierung von Einflussfaktoren und Zustandsveränderungen bei der Wasserversorgung. Wien: Bundesministerium für Nachhaltigkeit und Tourismus.

Hinweis des Verlags Der Verlag bleibt in Hinblick auf geografische Zuordnungen und Gebietsbezeichnungen in veröffentlichten Karten und Institutsadressen neutral. 